\section{JIBM}

Journal of International Business and Management (JIBM) Journal Homepage: https://rpajournals.com/jibm

\title{
Implementing Mckinsey 7S Model of Organizational Diagnosis and Planned Change, Best Western Italy Case Analysis
}

\author{
Ghadeer Odeh \\ The George Washington University, USA
}

\begin{abstract}
Best Western Italy operates under BW international Inc. a leading hotel and resort brand that provides high quality accommodation services in numerous countries across the globe. All of Best Western hotels are owned and managed independently. BW Italy is the brand's center for operations and reservation in the European market. It has gained recognition from its unique reservations services involving strategic partners to ensure their customers receive the best services at standardized rates. To reinforce its vision and mission, BW Italy management came up with a yearlong "Make a Difference" program to enhance employee commitment by aligning their goals to those of the company. This would entail organizational change which involves a system-wide transfer and application of behavioral science knowledge to the strategic development, enhancement, and reinforcement of the plans, process, and structures that result in organizational efficiency and effectiveness. The results included rearrangement of top management to establish a flatter organizational structure with improved distribution of leadership. A year after the program had been concluded, the General Manager was aware that its implementation had created colossal excitement and interaction among the employees who had taken part in it. However, four employees had refused to participate in the program while the company had recruited ten new employees after the program had ended. BW Italy needs to formulate a strategy to ensure that the "Make a Difference "program changes are internalized by its employees and institutionalized within the organization. The case analysis utilized secondary data acquired through a case study performed on BW Italy during the implementation of the program. Data was analyzed through the McKinsey 7s Model an effective tool used in analyzing organizational change. The McKinsey $7 \mathrm{~s}$ Model is an effective tool aimed at depicting how effectiveness can be achieved within an organization through the interaction of 7 different organizational elements namely structure, strategy, skill, system, shared values, style, and staff.
\end{abstract}

Keywords: Make a difference, Organizational change, Change program, Organizational goals, Mission and values, Employee commitment, Top management, Organizational diagnostic models, Performance outcomes

*Corresponding author: Ghadeer Odeh; Email: ghadeer013@gmail.com DOI: https://doi.org/10.37227/JIBM-2021-09-1438

\section{Introduction}

Best Western International, Inc. operates the Best Western Hotel and Resort, a leading global brand that provides accommodation services to all kinds of travelers. Best Western (BW) is headquartered 
in Phoenix, Arizona, and license over 4700 hotels globally. M.K Guertin founded it in 1946 in California, United States, and extensively expanded into a multinational brand operating in more than 100 countries. According to a recent report, the company has an estimated annual income of $\$ 2147.5 \mathrm{M}$. All Best Western hotels are owned and managed independently, making the company boast as the world's most prominent hotel family, not just a chain of hotels. Best Western Italy is the center for reservations and operations for Best Western International Inc. in the European market. Since its establishment, Best Western Italy has gained recognition from its exceptional reservation system and strategic partnerships that ensure its customers receive standardized services.

In 2011 the management of Best Western Italy came up with a yearlong program termed "Make a Difference" to reinforce the employee's commitment and align their vision and goals to the company's mission and values (Floernt-Tracey, 2013). Despite the positive results associated with the program, the General Manager pointed out a need for a psychodynamic plan that will energize the employees, making them responsible, accountable, and less dependent to ensure sustainable business success. This would entail organizational change which involves a system-wide transfer and application of behavioral science knowledge to the strategic development, enhancement, and reinforcement of the plans, process, and structures that result in organizational efficiency and effectiveness. It is both a field of scientific inquiry and an area of social action. In practice, organizational development covers a wide range of activities with an endless degree of differences (Cummings, \& Worley, 2014). This case study provides solid evidence on how to make a holistic organizational diagnosis by applying the McKinsey7s model to make a successful transformation on the macro level, to position Best Western Italy strategically in the market, and on the meso level to build a top management team, change the organizational structure to best fit the operational needs, and enrich jobs through task variety and enrichment methods.

\section{Literature Review}

Regardless of the size, an organization is always subject to environmental factors that influence its operations and performance outcomes (Merli, \& Preziosi, 2018; Phong \& Tung, 2021). This makes it necessary for managers to understand the prevailing environmental factors before formulating and implementing an organizational change program. One of Best Western hotels' greatest strengths is the independent property policy. This model is designed to give each hotel owner the maximum flexibility in decision-making and business operations to meet customers' specific needs (Candela, \& Figini, 2012). With the aim to live up to the standards of Best Western International, BW Italy operates like an enterprise within a global business group. The scope of its business activities included enhancing growth in the local market by enlarging the number of hotels associated with the brand and maintaining the brand's quality standards while ensuring all the independent hotel owners affiliated with the brand received their benefits. In 2011 Best Italy's General Manager Giovani Manzi saw the need to change the culture within the company. She noted that it was essential to implement a leadership development program for its employees focused on BW Italy's corporate mission and values and determine whether the employees had visions and goals aligned to that of the company.

In 2011, Giovanna Manzi, General Manager of BW Italy, decided it was time for a profound culture change inside the company. She wanted to implement a leadership development program for BW Italy employees, design a focus on BW Italy's corporate values and mission, and determine if the employees; the vision was aligned to the one of the companies. The General Manager collaborated with Massimiliano Saccareli, a leading executive leadership mentor, to develop the program to realize this goal. After detailed analysis, the team developed a yearlong multi-module "Make a Difference" program for all the 70 Best Western Italy employees. The program focused on helping each employee explore their professional and personal goals and dreams and work collectively to redesign the vision and mission of the organization. The aim was to enhance organization energy and motivation by encouraging trust and communication across all leadership levels. It resulted in a restructure of the top management level to establish a flatter organization with a more evenly distributed management, a rise in the Great Places to Work Institute Italia rankings, and organizational-based employee-initiated projects. 
The initial objective of the Make a Difference program was to make Best Western Italy an authentic organization with a workplace where employees can feel the authenticity of what they do and the vitality of their efforts and role. In the course of the program, all the members collaborated to codevelop a mission and a vision for Best Western Italy. This was to make each of them feel like a part of the company's vision and mission rather than having it imposed on them by the top management. It was also meant to help the members develop a shared communication and understanding of what they were doing as stakeholders in the organization. The program also offered a way out for the employees who would discover that their visions and goals did not match and align with those of Best Western Italy. Despite the financial demands associated with the program, BW Italy left the program to all employees as they felt it necessary to have everyone on board if they were to really realize the change. Finally, after the Make a Difference program, the participants came out with a poster designed as a puzzle capturing the work done to come up with a joint mission and vision for the organization. When put together, the puzzle reveals how each employee's fundamental motivation, energy, and goals are connected to Best Western Italy's future strategic plan.

\section{Problem Identification}

A year after the program had been concluded, the General Manager was aware that its implementation had created colossal excitement and interaction among the employees who had taken part in it. However, four employees had refused to participate in the program while the company had recruited ten new employees after the program had ended. This means that although the program had immense benefits to the company and its employees, these benefits could not be enjoyed thoroughly since some employees had no clue about the program. The program must be regular to ensure that the change is sustained within the organization and Best Western Italy continues to differentiate itself from other employers. However, this presents a huge problem due to the ongoing costs associated with maintaining the program over time.

\section{Methodology}

This case analysis followed the "Make a Difference" yearlong program involving all Best Western Italy employees aimed at helping staff members explore individual and professional goals and then collaborate to redesign the vision and mission of the company. The case analysis utilized secondary data acquired through a case study performed on BW Italy during the implementation of the program. Data was analyzed through the McKinsey $7 \mathrm{~s}$ Model an effective tool used in analyzing organizational change. The model helped depict how effectiveness can be achieved within an organization through the interaction of 7 different organizational elements.

\section{Results and Analysis}

It is evident that Best Western Italy has already undergone some significant changes; still, it is crucial to have conscious and well-planned change strategies. It is essential to formulate strategies that will prepare and help the organization maintain the resulting change to avoid disappointments and failure of programs on organizational change, which could mean wastage of time and resources ((Kanaane et al., 2015). The McKinsey 7s Model is an effective tool used in analyzing organizational change. It aims at depicting how effectiveness can be achieved within an organization through the interaction of 7 different organizational elements. These include structure, strategy, skill, system, shared values, style, and staff. The model's focus is based on the interconnectedness of all these elements categorized into soft and hard, meaning a domino effect that results when changing one aspect to maintain an effective balance. Centrally placing shared values reflects the vital impact of change in founder values in the other elements.

\section{Structure}

Structure refers to the company's organization in terms of leadership, command, accountability, and responsibility (Robbins Judge \& Vohra, 2019; Khan, Taher, and Islam, 
2021). It represents how the company is organized into units and divisions, including wellspelled out information on who is responsible for who. The structure is one of the most conspicuous features to change in a framework. Failure to create a cohesive and efficient structure undermines the ability to perform tasks necessary for attaining the stated goals and objectives. Different areas demonstrate the effectiveness of an organizational structure, including communication, assignment of responsibilities, and marketing of goods and services. In this case, BW Italy must strive to have a structure that will support its long-term strategy and, notably, create a close relationship between all the staff members to enhance employee and interdepartmental communication, responsibility, and accountability. Without a doubt, the boundary less structure will help BW Italy unlock its organizational energy by aligning the employees' goals to its long-term strategy.

\section{Strategy}

Strategy entails a well-formulated business plan that allows the company to create an action plan to realize sustainability supported by the organization's mission and values (Ali \& Anwar, 2021). BW Italy must implement a strategy that will provide direction for the whole company, including the top executives and the staff members. Having a clearly defined strategy will help all employees have common goals and follow the mission and values of the company without losing sight. The strategy takes into consideration all the things that a business can do and narrows them to what the business can do best. It also helps determine how money, time, and human resource are going to be applied for the benefit of the company. The top management at BW Italy should strive to establish a strategy that will be percolated down the line. This will help align the whole organization under one vision and objective from the executives to the junior staff. According to Mahajan (2019), various approaches would facilitate the effective implementation of the wanted strategic changes. First, as identified by the McKinsey 7s Model would be essential to work with the staff members who failed to participate in the "Make a Difference" program to align them with the company's strategy.

\section{Systems}

A system refers to the technical infrastructure within the company that facilitates workflow and decision-making. They are the procedures and processes that determine how to conduct business within the organization. It is the area that managers should focus on during organizational change. It will be necessary for BW Italy to have a system that supports connectedness within the company and help them fit to enhance individual and organizational effectiveness. It must also develop an organizational system that supports the goals of its employees through acquiring and using their feedback on goal clarity to formulate its long-term strategy (Cummings \& Worley, 2014). In line with the McKinsey 7s Model it is essential to have a system that regularly keeps track of the effectiveness of the organizational strategic objectives. BW Italy must also create distinctive system that will foster international expansion plans through differentiation and diversification to adjacent markets to meet the demand gap.

\section{Skills}

Skills refer to the competences and capabilities of the company that help the employee perform at their best and achieve their objectives for the company's overall success ((Cummings \& Worley, 2014). It is vital for BW Italy to have a system that will evaluate the performance of all the employees and provide a detailed job description considering task diversity, task identity, and autonomy this requires employee rotation to acquire new skills and simultaneously excel in their core tasks. This 
will boost creativity and effectiveness in all business activities. According to Cummings and Worley (2014), both the mentoring and onboarding processes are part of the institutionalization process through which organizations must apply socialization strategies to train new staff members to ensure efficiency, happiness, and productivity at work. Moreover, according to the Maslow Hierarchy (Tanner, 2018) it is crucial to motivate employees by meeting their needs, by providing a psychologically safe and secure environment to foster supportive relationships, reaching work-life balance, and providing a sense of affiliation to employees through activities. It would also be necessary for BW Italy to develop a support initiative. The often question that arise during organizational change is what skills the firm will need to strengthen the new structure or strategy. This could be done by pairing recruits with old employees who had participated in the Make a Difference program. It helps the newcomers have an understanding of the organizational culture at Best Western Italy, allowing the new values to remain strong. It would also be essential to create peer-to-peer mentorship groups rather than managerial relationships for employees from differing cultures to help them adapt to diversity. It facilitates greater flexibility and responsiveness among the staff helping in the exchange of ideas and allowing more integration of departments which can improve trust, mutual interest, and flow of communication (Dess, et. al 2014).

\section{Style}

Style entails the tone and attitude towards work set by the top management through how they interact with the other staff member and make decisions. BW Italy managers must show commitment to leadership to facilitate effectiveness, employee engagement, and satisfaction by establishing policies that support collective planning (Shumi \& Begum, 2021). According to Shin et al. (2015), leaders are critical to any form of organizational transformation. As highlighted by the McKinsey 7s Model efforts to sustain any organizational changes begin with the top management taking charge and encouraging these kinds of programs while serving as examples. Motivation from top management is crucial as organization members tend to revert to old behaviors and processes without sustained reinforcement and support (Cummings, \& Worley, 2014; Bartholomeusz \& Edirisooriya, 2021). The communication style adopted by leaders will play a key role in ensuring that all the employees have a common mindset as the program aims. During an organizational change program managers, must provide their staff with individual attention to increasing optimism about change, including encouraging the employees to do away with their personal interests for the sake of teamwork and the organization in general through the spirit of transformation.

\section{Staff}

The staff refers to all the human recourse including the management and the employees. It is the element concerned with the kind and number of employees that the organization needs, how they will be recruited, trained and motivated. It is essential to hire employees who are culturally and morally compatible, and how well they can cultivate the organizational values and work with a team (Cecily D. Cooper, 2017). It is crucial that BW Italy create an effective workforce plan to align its strategy to that of its staff members. Once the staff are recruited and trained it will be crucial to evaluate the impact that the "Make a Difference" program has had to ensure success for all actions. There are various performance indicators, including performance, value consensus, and normative consensus, that can evaluate the degree of change and persistence among the employees (Cummings \& Worley, 2014). New employees can easily be influenced (Ribarsky \& Hammonds, 2019). This makes it crucial to understand and facilitate their adjustment to the organization and maximize the expected outcomes to meet the skill demand gap in the future (Praise \& Kah, 2020). It would also be necessary for the company to include the implementation feedback for planned changes and future programs (Cummings, \& Worley, 2014). Creating functional strategies can regulate the flow of work and assess the overall performance. 


\section{Shared Values}

The shared values refer to the mission, values, and objectives that form the organizational foundation and play a significant role in aligning all fundamental elements to sustain an effective corporate design (Wong \& Avery, 2008; Arieli, Sagiv \& Roccas, 2020). In this perspective, Best Western Italy must maintain the organizational culture it creates by through implementing the Make a Difference program. When the changes begin to be felt, and the employees have embraced the new operational approaches, it will be easy for the company to perform as the employees will have adopted common values. This involves ensuring that the changes learned through the program are applied all the time and incorporated into the company's daily business operations. With the new sense of belonging and job stability, the employees become more comfortable and confident with the latest working models (Cummings, \& Worley, 2014). As a result, Best Western Italy needs to ensure that the Make a Difference program changes are internalized by its employees and institutionalized within the organization. Additionally, conducting surveys on shared values regularly will offer detailed feedback on job enrichment opportunity based on motivational approach that focuses on responsibility, performance and feedback as a motivator to increase staff engagement and satisfaction (Valentijn, Schepman, Opheij \& Bruijnzeels, 2013; Zonneveld, Driessen, Stüssgen, \& Minkman, 2018). According to (Carucci, 2017), the research revealed that employee engagement in decision making will create a healthy workplace and increase creativity and retention levels.

The steps mentioned earlier do not necessarily include the training budgets. As undertaking this program can be costly, to make the organizational change more present and sustainable, BW Italy can consider smaller versions of the program, which are less expensive in terms of time and resources. This could be done by holding the Make a Difference program during an annual meeting, including all the members to review the employee and organization's values and vision. Regular pieces of training along the way could be applied to remind the employees about the Make a Difference program to improve their knowledge, leadership skills, and teamwork. Although all these initiatives require an additional budget, BW Italy should be aware that using the change program and facilitating its sustainability enhance the productivity of its employees, meaning that the company stands to benefit in terms of revenues a competitive brand name. With increased revenues, Best Western Italy can allocate back more resources towards employee training resulting in proliferating growth and expansion.

\section{Conclusion}

The "Make a Difference" yearlong program that involved all Best Western Italy employees aimed at helping staff members explore individual and professional goals and then collaborate to redesign the vision and mission of the company. The objective was to unravel organizational energy and boost trust and communication across leadership levels. The program was successful and resulted in various benefits including rearrangement of top management to establish a flatter organizational structure with improved distribution of leadership and improvement as one of the best places to work in Italy. The McKinsey 7s Model provides a diagnostic approach to create a change management plan focusing on human capital and passion and aligning them with BW's strategy, the output will ensure achieving the strategic objectives of BW Italy, and monitoring employee performance, and engagement.

We concluded that the McKinsey 7s Model provides a holistic approach and interconnectedness between individual, group, and organizational level variables to coincide with BW strategy to effectively unlock the organization energy. As a recommendation, we would encourage BW Italy to monitor external environment trends, and conduct periodic core competency evaluation to ensure sustainability and differentiation in the marketplace. It would also be important for BW Italy to devise an open communication channel for the employees who did not participate in the program to learn its advantages and the intended outcomes through different. This will help the managers to acquire staff buy-in while maintaining the initial commitment to change. Best Western Italy should consider initiating an onboarding process to familiarize the newcomers with the 
program's purpose and benefits concerning the new employees and others who will continue joining. It is also advisable to have planning interventions which finding strategies to fill the future skillsdemand gap and, identify functional norms to facilitate performance. BW Italy need to lead by example by being proactive in maintaining their employee's commitment to organizational change and improvement to realize success.

\section{References}

Ali, B. J., \& Anwar, G. (2021). Business strategy: The influence of Strategic Competitiveness on competitive advantage. International Journal of Electrical, Electronics and Computers, 6(2).

Arieli, S., Sagiv, L., \& Roccas, S. (2020). Values at work: The impact of personal values in organisations. Applied Psychology, 69(2), 230-275.

Bartholomeusz, R. A., \& Edirisooriya, W. A. (2021). Does Meaningful Work Fuel the Altruistic Behavior of Employees in the Contemporary World of Work? Evidence from Private Sector Banks in Sri Lanka. Journal of International Business and Management, 4(6), 01-08.

Candela, G., \& Figini, P. (2012). The economics of tourism destinations. In The economics of tourism destinations (pp. 73-130). Springer, Berlin, Heidelberg.

Cummings, T. G., \& Worley, C. G. (2014). Organization development and change. Cengage learning.

Carucci, R. (2017). How to Nourish Your Team's Creativity, Harvard Business Review. Retrieved from https://hbr.org/2017/05/how-to-nourish-your-teams-creativity.

Cecily D. Cooper, D. H. (2017). Mastering Organizational Behavior. 646. Retrieved from https://catalog.flatworldknowledge.com/catalog/editions/cooper_ob-masteringorganizational-behavior-14-0

Dess, G., Eisner, A., Lumpkin, T., \& McNamara, G. (2013). Strategic management: Creating competitive advantages (7th ed.). New York City, NY: McGraw-Hill.

Floernt-Tracey, E. (2013). Best Western Italy. (A): Creating an authentizotic organization by putting people first. Retrieved from http://hbsp.harvard.edu

Kanaane, R., Akabane, G., Peterossi, H., \& Endler, D. C. N. (2015). Organizational change management in a strategic perspective. American Journal of Management, 15(2), 88.

Khan, A. Taher, M. A. and Islam M A. (2021) Human Resource Management (HRM), Abir Publication, Dhaka, Bangladesh

Mahajan, A. (2019). Relationship of Talent Management with Organizational Culture: A Discussion Paper. Indian Journal of Industrial Relations, 54(3).

Praise, A. S., \& Kah, J. M. (2020). Talent Management Practices in Institutions: Impact of Recruitment and Culture on Employee Performance. Journal of International Business and Management, 3(3), 01-14.

Ribarsky, E., \& Hammonds, J. (2019). Gossiping for the Good of It? Examining the Link between Gossip and Organizational Socialization. Kentucky Journal of Communication, 38(1).

Shin, J., Seo, M. G., Shapiro, D. L., \& Taylor, M. S. (2015). Maintaining employees' commitment to organizational change: The role of leaders' informational justice and transformational leadership. The Journal of Applied Behavioral Science, 51(4), 501-528

Merli, R., \& Preziosi, M. (2018). The EMAS impasse: Factors influencing Italian organizations to withdraw or renew the registration. Journal of Cleaner Production, 172, 4532-4543.

Phong, L. B \& Tung, H. T. (2021). Influences of Organizational Factors on Organizational Capability for Innovation: An empirical Study from Vietnamese Firms. Journal of International Business and Management, 4(6), 01-14.

Robbins, S. P., Judge, T. A., \& Vohra, N. (2019) Organizational behavior. 18" edition. Pearson Education.

Shumi, R. A., \& Begum, S. (2021). Employee Engagement Practices in Banking of Bangladesh: An Analysis and Evaluation of Critical Success Factors. Journal of International Business and Management, 4(8), 01-15. 
Tanner, R. (2018), Motivation -Applying Maslow's Hierarchy of Needs Theory, Management is a Journey, Retrieved from https://managementisajourney.com/motivation-applying-maslowshierarchy-of-needs-theory/

Valentijn, P. P., Schepman, S. M., Opheij, W., \& Bruijnzeels, M. A. (2013). Understanding integrated care: a comprehensive conceptual framework based on the integrative functions of primary care. International journal of integrated care, 13. pp. 1-12.

Wong, L., \& Avery, G. C. (2008). Creating sustainability in organisations: Beyond being green. International Journal of Interdisciplinary Social Sciences, 3(2), 68-74.

Zonneveld, N., Driessen, N., Stüssgen, R. A., \& Minkman, M. M. (2018). Values of integrated care: a systematic review. International Journal of Integrated Care, 18(4). pp.1-12. 